\title{
El riesgo de reintroducción del sarampión en México
}

\author{
José Alberto Díaz-Quiñónez*
}

División de Estudios de Posgrado, Facultad de Medicina, Universidad Nacional Autónoma de México, Ciudad de México, México

L'ignorance du passé ne se borne pas à nuire à la connaissance du présent; elle compromet, dans le présent, l'action même.

MARC BLOCH

En 1531 ocurrió la primera epidemia descrita de tepitonzahuatl (sarampión) en la Nueva España. Esta "pestilencia" se esparció rápidamente por los pueblos indígenas del centro de México. Ese mismo año sucedieron las apariciones de la Virgen de Guadalupe y las "consecuentes curaciones" de los nativos recién convertidos. ${ }^{1}$ La protectora de los indígenas ante las enfermedades epidémicas en el siglo XVI se convirtió en la patrona que - desde el siglo XVIII - es considerada el escudo de armas con el que nuestro país se defiende de todos los males. ${ }^{2}$

El sarampión es una de las virosis agudas más infecciosas y transmisibles por vía aérea. Se manifiesta con fiebre, rinitis, conjuntivitis, tos y enantema patognomónico, seguido de exantema maculopapular centrífugo, que termina en convalecencia con descamación furfurácea. ${ }^{3}$ Los niños pequeños no vacunados son las principales víctimas de complicaciones neurológicas y neumonías, ambas incapacitantes y letales. La infección por el virus del sarampión compromete la respuesta y la memoria inmunológica contra otros patógenos, estableciendo estados de inmunosupresión y "amnesia inmune". ${ }^{4}$ La vacunación sistemática de los niños contra el sarampión, combinada con estrategias de inmunización masiva en países con elevada incidencia y mortalidad, es fundamental para reducir la mortalidad. La vacuna contra el sarampión, que se ha utilizado desde hace más de 50 años, ha demostrado ser segura, eficaz y costo-efectiva; además, genera otros beneficios en el desarrollo de los niños, no solo en la primera infancia. ${ }^{5}$
En México, la notificación oficial del sarampión inició en 1941. Antes de la década de 1950, la enfermedad se encontraba entre las principales causas de morbilidad y mortalidad, con la aparición de epidemias cada dos o tres años. ${ }^{6}$ A partir de 1973, el panorama epidemiológico cambió sustancialmente después de iniciar el Programa Nacional de Inmunizaciones. Los casos disminuyeron notablemente y los periodos interepidémicos se prolongaron. Al igual que el resto del continente, México enfrentó una nueva epidemia de sarampión entre 1989 y 1990. De manera decidida, México se comprometió ante los organismos internacionales y los países de la región a establecer programas de eliminación. Con la implementación de una serie de estrategias de vacunación, como parte de la política pública, el sarampión fue eliminado de nuestro país. ${ }^{7}$ El compromiso, la visión y un enorme esfuerzo de autoridades y trabajadores de la salud posicionó al programa de vacunación mexicano como uno de los mejores y más reconocidos en el mundo.

Desde 1996 no se han presentado casos autóctonos de sarampión en el país. La vigilancia virológica por el Instituto de Diagnóstico y Referencia Epidemiológicos "Dr. Manuel Martínez Báez" ha permitido confirmar todos los casos importados y, mediante la identificación de los genotipos virales, asociarlos a los países de origen. Así, entre los casos importados se han identificado los genotipos D6, H1, D9, B3, D4 y D8 con transmisión en Estados Unidos y Canadá, Francia y otros países europeos, China, Japón y la península de Corea. ${ }^{8}$

En 2016, la región de las Américas fue declarada libre de sarampión por la Organización Mundial de la Salud. ${ }^{9}$ Sin embrago, la ocurrencia de brotes de sarampión en varias regiones del mundo y el
Correspondencia:

*José Alberto Díaz-Quiñónez

E-mail: adiazq@unam.mx
Fecha de recepción: 30-08-2019

Fecha de aceptación: 03-09-2019

DOI: 10.24875/GMM.19005496
Gac Med Mex. 2019:155:455-456

Disponible en PubMed

www.gacetamedicademexico.com 
movimiento de personas infectadas en países donde continúa la transmisión representa un riesgo latente para los países que tienen baja cobertura de vacunación. Los grupos antivacunas, las desatinadas decisiones en políticas de salud pública en algunos países, además de la migración desordenada y otros determinantes sociales amenazan las casi tres décadas de esfuerzo coordinado en nuestra región.

Recientemente, la transmisión sostenida del sarampión llevó a la declaración de la pérdida del estatus de eliminación en Europa..$^{10}$ La Organización Mundial de la Salud activó, además, una respuesta de emergencia grado 2, designación que permite movilizar recursos técnicos, financieros y humanos para apoyar a los países afectados.

De acuerdo con datos de la Dirección General de Información en Salud, ${ }^{11}$ la Organización para la Cooperación y el Desarrollo Económico ${ }^{12}$ y la Organización Mundial de la Salud,,$^{13}$ las coberturas de vacunación en México -que durante muchos años se mantuvieron por arriba del indicador internacional- han disminuido considerablemente en años recientes. Así, a la acumulación de poblaciones en riesgo se suman la escasez de vacuna ${ }^{14}$ y la crisis de migración en el país. ${ }^{15}$

A cinco siglos del arribo del sarampión a las Américas, la política pública en salud enfrenta un reto mayúsculo ante la posible reintroducción en México. Es momento de establecer alianzas e implementar iniciativas en todos los países de origen, tránsito y destino de las poblaciones migrantes, para dirigir las acciones de vigilancia y vacunación. ${ }^{16}$ Es tiempo de reentrenar a los clínicos en el primer nivel de atención y fortalecer la red nacional de laboratorios de salud pública para la confirmación de los casos. ${ }^{17}$ Este es el momento y la oportunidad de fortalecer a la salud pública mexicana.

\section{Bibliografía}

1. De Mendieta J. Historia eclesiástica indiana, vol. III. México: Salvador Chávez Hayhoe; 1945. p. 172.

2. Cabrera y Quintero C. Escudo de armas de México. Escrito por el presbítero para conmemorar el final de la funesta epidemia de matlazahuatl que asoló a la Nueva España entre 1736 y 1738. México (1746): Edición facsimilar; 1981.

3. Gherson AA. Measles virus. 2031-38. En: Mandell GL, Bennet JE, Dolin R, editores. Principles and practice of infectious diseases. Sexta edición. Elsevier, Churchill, Livingston; 2005.

4. Mina MJ, Metcalf CJ, de Swart RL, Osterhaus AD, Grenfell BT. Longterm measles-induced immunomodulation increases overall childhood infectious disease mortality. Science. 2015;348(6235):694-699. DOI: 10.1126/science.aaa3662.

5. Nandi A, Shet A, Behrman JR, Black MM, Bloom DE, Laxminarayan R. Anthropometric, cognitive, and schooling benefits of measles vaccination: Longitudinal cohort analysis in Ethiopia, India, and Vietnam. Vaccine. 2019;37(31):4336-4343. DOI: 10.1016/j.vaccine.2019.06.025.

6. López-Alonso M. Measuring up: a history of living standards in Mexico 1850-1950. Social Science History. Stanford, CA: Stanford University Press; 2012. p. 148-149.

7. Santos JI, Nakamura MA, Godoy MV, Kuri P, Lucas CA, Conyer RT. Measles in Mexico, 1941-2001: interruption of endemic transmission and lessons learned. J Infect Dis. 2004;189 Suppl 1:S243-S250.

8. Díaz-Quiñónez JA. The right wall we need to build. EC Microbiology. 2017;7(1):1-3.

9. Pan American Health Organization [sitio web]. Region of the Americas is declared free of measles. Pan American Health Organization; 2016. [Consultado 2019 Ago 29]. Disponible en: https://www.paho.org/hq/index. php?option=com_content\&view=article\&id=12528:region-americas-declared-free-measles\&ltemid=1926\&lang=en

10. World Health Organizatión [sitio web]. Measles in Europe: European Region loses ground in effort to eliminate measles. World Health Organization; 2019. [Consultado 2019 Ago 29]. Disponible en: http://www. euro.who.int/en/media-centre/sections/press-releases/2019/european-region-loses-ground-in-effort-to-eliminate-measles.

11. Secretaría de Salud [sitio web]. Concentrado por unidad médica. [Consultado 2019 Ago 29]. Disponible en: http://www.dgis.salud.gob.mx/contenidos/basesdedatos/bdc_serviciossis_gobmx.html.

12. OECDiLibrary [sitio web]. Child vaccination rates (indicator). [Consultado 2019 Ago 29]. DOI: 10.1787/b23c7d13-en

13. Pan American Health Organization. [Sitio web]. Coverage by vaccine. [Consultado 2019 Ago 29]. Disponible en: http://ais.paho.org/imm/IM JRF_COVERAGE.asp

14. Jiménez H. "SSa reconoce desabasto de vacunas contra sarampión". El Universal, 9 de agosto de 2019. [Consultado 2019 Ago 29]. Disponible en: www.eluniversal.com.mx/nacion/sociedad/ssa-reconoce-desabasto-de-vacunas-contra-sarampion

15. United Nations High Commissioner for Refugees (UNHCR) [sitio web]. The UN refugee agency. Fact sheet. Mexico. 2019. Disponible en: http:// reporting.unhcr.org/sites/default/files/UNHCR\%20Factsheet\%20Mexico\%20-\%20April\%202019.pdf

16. Thakkar N, Gilani SSA, Hasan Q, McCarthy KA. Decreasing measles burden by optimizing campaign timing. Proc Natl Acad Sci USA. 2019;116(22):11069-11073. DOI: 10.1073/pnas.1818433116.

17. Román-Pedroza JF, Cruz-Ramírez E, Landín-Martínez KE, Salas-García M, López-Ortiz E, Ramírez-González JE, López-Martínez I, Díaz-Quiñónez JA. Algoritmo diagnóstico para la confirmación de casos de sarampión y rubéola en México. Gac Med Mex. 2019;155(5):532-536. 